Arq. Bras. Med. Vet. Zootec., v.59, n.6, p.1531-1537, 2007

\title{
Padrão de fermentação da silagem de cinco genótipos de sorgo
}

[Fermentation pattern of silages from five sorghum genotypes]

\author{
C.G.M. Ribeiro ${ }^{1}$, L.C. Gonçalves ${ }^{2}$, J.A.S Rodrigues ${ }^{3}$, N.M. Rodriguez ${ }^{2}$, I. Borges ${ }^{2}$, A.L.C.C.Borges ${ }^{2}$, \\ E.O.S. Saliba ${ }^{2}$, G.H.F. Castro ${ }^{1}$, G.O. Ribeiro Junior ${ }^{4}$ \\ ${ }^{1}$ Aluno de pós-graduação - EV-UFMG - Belo Horizonte, MG \\ ${ }^{2}$ Escola de Veterinária - UFMG \\ Caixa Postal 567 \\ 30123-970 - Belo Horizonte, MG \\ ${ }^{3}$ Embrapa Milho e Sorgo - Sete Lagoas, MG \\ ${ }^{4}$ Aluno de graduação - EV-UFMG - Belo Horizonte, MG
}

\begin{abstract}
RESUMO
Foram utilizados cinco genótipos de sorgo de colmo seco, sendo dois híbridos comerciais (Volumax e BR 700) e três novos híbridos experimentais desenvolvidos pela Embrapa Milho e Sorgo (0249341, 0249317 e 0249339), com o objetivo de determinar, no material original e em sete tempos de abertura subseqüentes à ensilagem $(1,3,5,7,14,28$ e 56), as porcentagens de matéria seca, proteína bruta, nitrogênio amoniacal em relação ao nitrogênio total, $\mathrm{pH}$ e carboidratos solúveis em álcool. Os valores de matéria seca dos materiais originais foram semelhantes aos das silagens em todos os dias de abertura. Os valores de matéria seca das silagens variaram entre 26,03 e $41,13 \%$ com média $32,65 \%$. Os valores de proteína bruta foram menores no $56^{\circ}$ dia de abertura comparados aos dos materiais originais. A degradação dos carboidratos solúveis foi intensa até o quinto dia de fermentação. Os valores de nitrogênio amoniacal foram baixos e estáveis até o $28^{\circ}$ dia pós-ensilagem, com pequeno aumento no $56^{\circ}$ dia e a variação neste último período foi de 2,01 a 3,66\%. Os valores de $\mathrm{pH}$ variaram de 3,69 a 4,52 e sua estabilização se deu no quinto dia pós-ensilagem. De maneira geral, os híbridos avaliados apresentaram potencial para serem utilizados na forma de silagem.
\end{abstract}

Palavras-chave: sorgo, silagem, padrão de fermentação

\begin{abstract}
Five sorghum genotypes, two comercial hibrids (Volumax and BR 700) and three experimental hibrids developed by Embrapa Milho e Sorgo (0249341, 0249317 and 0249339), were used in order to determine in both the genotypes and their silages after seven different opening times the contents of dry matter, crude protein, amoniacal nitrogen, $\mathrm{pH}$ and alcohol soluble carbohydrates. The dry matter values were not modified during the ensilage. The dry matter values of the silages ranged from 26.03 to $41.13 \%$, with an average of $32.65 \%$. The crude protein values were smaller after the $56^{\text {th }}$ day of ensilage than the original genotype. The soluble carbohydrates degradation was intensed on the $5^{\text {th }}$ day of silage fermentation. The amoniacal nitrogen values were small and estabilized on the $28^{\text {th }}$ day after ensilage, with a small increase on the $56^{\text {th }}$ day. The pH values ranged from 3.69 to 4.52 , stabilizating on the $5^{\text {th }}$ day after ensilage. According to the results, the hybrids showed high potential for silage use.
\end{abstract}

Keywords: sorghum, silage, fermentation profile

Recebido em 26 de fevereiro de 2007

Aceito em 3 de outubro de 2007

Autor para correspondência (corresponding author)

E-mail: luciocg@vet.ufmg.br 


\section{INTRODUÇÃO}

Uma silagem de alta qualidade é produzida se forem seguidas recomendações básicas durante a sua confecção, entre as quais se destacam o tamanho da partícula, a eficiente e a imediata vedação. Mas a determinação do momento ideal de colheita é o ponto critico para se obter silagem com alto valor nutritivo e adequado teor de matéria seca, a fim de favorecer o processo fermentativo. Paiva (1976) recomenda teores de $30-35 \%$ de MS no material a ser ensilado. Mcdonald et al. (1991) citam que os valores de matéria seca devem ser maiores que $25 \%$ para evitar maiores perdas por efluentes. Meskee et al. (1993) obtiveram boas silagens de sorgo com teores de matéria seca variando de 20 a $29 \%$. Desta forma, o teor de matéria seca da planta constitui fator determinante no processo de fermentação da silagem. Esse teor varia com a idade de corte e com a natureza do colmo da folha (Carvalho et al., 1992). Normalmente híbridos de sorgo com colmo seco elevam o teor de matéria seca mais precocemente com a maturação.

Entre os fatores que influenciam a proteólise, durante o processo de ensilagem, o $\mathrm{pH}$, o tempo de ensilagem, o conteúdo de matéria seca e a temperatura são de maior relevância (Mckersie, 1985). Um teor de nitrogênio amoniacal, menor que $10 \%$ do nitrogênio total, indica que o processo de armazenamento não resultou em degradação excessiva da proteína em amônia. Valor maior que $15 \%$ significa que houve quebra considerável de proteína (AFRC, 1987).

Silagens bem preservadas apresentam $\mathrm{pH}$ que variam entre 3,7 e 4,2. Silagens mal preservadas possuem alto $\mathrm{pH}$, entre 5 e 7 e têm concentrações consideráveis de ácido acético e butírico (Mcdonald et al., 1991).

O principal substrato para a fermentação láctica no silo são os carboidratos solúveis (Henderson, 1993). O grupo dos carboidratos solúveis é representado por monossacarídeos, dissacarídeos e alguns polissacarídeos presentes no conteúdo celular vegetal. Segundo Gourley e Lusk (1977), são necessários de 6 a $8 \%$ de carboidratos solúveis na matéria seca do material verde para que ocorra uma adequada fermentação. Em condições experimentais, níveis de $2,5 \%$ de carboidratos solúveis na matéria natural foram necessários para abaixar o $\mathrm{pH}$ a valores menores que 4,2, e conservar os níveis de nitrogênio amoniacal abaixo de $8 \%$ do nitrogênio total (Petterson e Lindgren, 1989).

O objetivo deste trabalho foi avaliar cinco genótipos de sorgo de colmo seco para a produção de silagem por meio do padrão de fermentação e pela variação dos teores de matéria seca, proteína bruta e carboidratos solúveis em álcool, em diferentes períodos de fermentação.

\section{MATERIAL E MÉTODOS}

Cinco genótipos de sorgo foram plantados, colhidos e ensilados nas dependências da Embrapa Milho e Sorgo, localizada a $19^{\circ} 28^{\prime} \mathrm{de}$ latitude sul, $44^{\circ} 15^{\prime}$ de longitude oeste de Greenwich, a uma altitude de 732 metros, no município de Sete Lagoas, Minas Gerais. O plantio foi realizado no dia $11 / 11 / 2002$, em canteiros experimentais compostos por duas fileiras de $5 \mathrm{~m}$ com espaçamento de $0,70 \mathrm{~cm}$. Cada genótipo foi plantado em três canteiros, que constituíram as suas repetições (parcelas). A adubação de plantio foi equivalente a $350 \mathrm{~kg} / \mathrm{ha}$ de 8-28-16 (NPK) mais $\mathrm{Zn}^{+}$e a de cobertura a $100 \mathrm{~kg} / \mathrm{ha}$ de uréia 40 dias após o plantio, de acordo com a análise do solo e a necessidade da cultura. A colheita foi realizada no dia 20/02/03 e os cortes foram feitos a altura de $20 \mathrm{~cm}$ do solo.

Os cinco genótipos avaliados foram: $\mathrm{Br} 700$ (H1), Volumax (H2), 0249341 (H3), 0249317 (H4) e 0249339 (H5), sendo que os genótipos H3 e H5 foram obtidos por ensaio de cruzamentos experimentais do híbrido macho 030 e o $\mathrm{H} 4$ obtido do híbrido macho 038. Os híbridos 030 e 038 são de porte alto e possuem o colmo seco. Volumax e BR 700 são testemunhas comerciais, sendo que o BR 700 possui tanino.

Para se avaliarem a qualidade e o perfil de fermentação das silagens de sorgo, procedeu-se a ensilagem dos materiais colhidos após 101 dias do plantio. O material foi picado em picadeira estacionária $^{1}$ em partículas de tamanho médio de $2 \mathrm{~cm}$, homogeneizado manualmente $\mathrm{e}$ imediatamente ensilado em silo de laboratório (Araújo et. al., 2007). Retirou-se amostra do material picado para posterior analise como

${ }^{1}$ Nogueira - modelo DPM-4 - São João da Boa Vista, Brasil 
material original (P0). O restante foi ensilado procedendo-se a abertura nos tempos: um, três, cinco, sete, 14, 28 e 56 dias pós ensilagem.

Foram utilizados 90 silos, confeccionados de acordo com Araújo et al. (2007). Nesses, os materiais foram compactados com auxílio de um soquete de madeira, de modo a se conseguir densidade entre 500 a $600 \mathrm{~kg} / \mathrm{m}^{3}$. Após a ensilagem os silos foram tampados, lacrados com fita crepe, pesados e mantidos à temperatura ambiente até o momento de sua abertura. Antes da abertura, os silos foram pesados. Todo o conteúdo foi homogeneizado em bandeja metálica previamente limpa e seca. Uma parte do material foi pesada e incubada em estufa de ventilação forçada por 72 horas, para determinação da matéria pré-seca a $65^{\circ} \mathrm{C}$ (Official..., 1980). O material restante foi prensado em prensa hidráulica ${ }^{2}$ para a extração do suco da silagem. Após determinação da matéria pré-seca, os materiais foram moídos ${ }^{3} \mathrm{em}$ peneira de $1 \mathrm{~mm}$ e acondicionados em frascos de polietileno com tampa de rosca.

Nas amostras pré-secas dos materiais originais e das silagens foram determinados os teores de matéria seca $(\mathrm{MS})$ em estufa a $105^{\circ} \mathrm{C}$, proteína bruta (PB) (Official..., 1980) e carboidratos solúveis (CHOs) (Bailey, 1967). O suco da silagem foi imediatamente utilizado para as análises de $\mathrm{pH}$ e teores de nitrogênio amoniacal. Os valores de $\mathrm{pH}$ foram medidos em potenciômetro ${ }^{4}$ com escala expandida. $\mathrm{O}$ teor de nitrogênio amoniacal foi obtido por destilação com óxido de magnésio e cloreto de cálcio, empregando-se solução receptora de ácido bórico e titulação com solução de ácido clorídrico $0,1 \mathrm{~N}$. $\mathrm{O}$ teor de nitrogênio amoniacal foi inicialmente obtido em miligramas por $100 \mathrm{ml}$ de suco de silagem $\left(\mathrm{N}-\mathrm{NH}_{3}\right.$ em mg\%). Posteriormente com as análises de matéria seca e proteína bruta o nitrogênio amoniacal foi expresso em porcentagem do nitrogênio total na base da matéria seca $\left(\mathrm{N}-\mathrm{NH}_{3} / \mathrm{NT}\right.$ em \%).

O delineamento utilizado foi inteiramente casualizado com fatorial $5 \times 8$ (cinco híbridos e oito tempos) para as análises de MS, PB e CHOs. Para as análises de $\mathrm{pH}$ e $\mathrm{N}-\mathrm{NH}_{3} / \mathrm{NT}$ o esquema

${ }^{2}$ Carver - modelo C - Wabash, EUA

${ }^{3}$ Willey, Apax - Diadema, Brasil

${ }^{4}$ Beckman Expandomatic SS-2 - EUA foi um fatorial $5 \times 7$ (cinco híbridos e sete tempos de abertura), pois não se procedem a essas análises no dia 0 . Os dados obtidos foram submetidos à análise de variância utilizando-se o software SAEG 8.0 (Sistema..., 1998) e as médias foram comparadas por meio do teste SNK ao nível de significância de 5\%.

\section{RESULTADOS E DISCUSSÃO}

A Tab. 1 mostra a percentagem de MS do material original e das silagens nos diferentes dias de abertura. Os teores de MS variaram entre 26,03 e 41,13\%. Não houve interação entre genótipos e dia de abertura. O teor de MS de H1 foi maior que os dos demais híbridos $(\mathrm{P}<0,05)$, seguido por $\mathrm{H} 5$ que foi maior que $\mathrm{H} 2, \mathrm{H} 3$ e $\mathrm{H} 4$ $(\mathrm{P}<0,05)$. H2 foi superior aos H3 e H4 $(\mathrm{P}<0,05)$ que foram semelhantes entre si $(\mathrm{P}>0,05)$. Não foram observadas alterações nos valores de MS das silagens nos diferentes períodos de abertura (0 a 56 dias), isto é, a matéria seca se manteve estável.

Os valores de MS obtidos foram maiores que os relatados por Silva (1996), que ao trabalhar com sorgos de porte alto, médio e baixo observou médias de 25,27 a 31,02\%. Borges (1995) obteve valores de MS que variaram entre 21,86 e $27,27 \%$, ao estudar híbridos de porte alto, porém com diferentes teores de suculência de colmo. Valores semelhantes para a MS das silagens de sorgo foram obtidos por Araújo (2002) em híbridos de duplo propósito.

Paiva (1976) constatou que a porcentagem de MS do sorgo varia de acordo com a idade de corte, natureza do colmo (suculência) e com a proporção dos diferentes constituintes dessa forrageira (colmo, folha e panícula) e recomendou valores de MS entre 30 a 35\% para silagem de boa qualidade. Pizarro (1978) citou valores entre 28 a $38 \%$, porém McDonald et al. (1991) afirmaram que um teor de matéria seca igual ou superior a $20 \%$ associado a um adequado teor de carboidratos solúveis seriam suficientes para se produzir uma silagem de boa qualidade.

Pressupõe-se que os altos valores de MS encontrados neste trabalho podem estar relacionados à baixa suculência dos colmos nos híbridos estudados. Isso sugere que a umidade dos híbridos era adequada para ensilagem. 
Tabela 1. Matéria seca (\%) do material original (PO) e das silagens dos cinco genótipos de sorgo, de acordo com o tempo de ensilagem

\begin{tabular}{cccccccccc}
\hline & \multicolumn{10}{c}{ Dia de abertura do silo } \\
Híbrido & P0 & 1 & 3 & 5 & 7 & 14 & 28 & 56 & Média \\
\hline H1 & 37,51 & 37,29 & 40,17 & 41,13 & 39,58 & 40,00 & 41,06 & 39,22 & $39,49 \mathrm{a}$ \\
H2 & 32,10 & 30,42 & 32,18 & 33,27 & 31,90 & 31,79 & 32,86 & 30,75 & $31,91 \mathrm{c}$ \\
H3 & 26,03 & 27,28 & 28,22 & 29,07 & 28,61 & 29,04 & 29,93 & 28,00 & $28,27 \mathrm{~d}$ \\
H4 & 26,05 & 26,66 & 30,63 & 28,93 & 29,29 & 28,81 & 30,01 & 27,06 & $28,43 \mathrm{~d}$ \\
H5 & 34,17 & 33,75 & 34,47 & 35,19 & 36,09 & 37,28 & 34,83 & 35,44 & $35,15 \mathrm{~b}$ \\
Média & $31,17 \mathrm{~A}$ & $31,08 \mathrm{~A}$ & $33,13 \mathrm{~A}$ & $33,52 \mathrm{~A}$ & $33,09 \mathrm{~A}$ & $33,38 \mathrm{~A}$ & $33,74 \mathrm{~A}$ & $32,09 \mathrm{~A}$ & 32,65 \\
\hline
\end{tabular}

H1= BR700, H2= Volumax, H3= 0249341, H4= 0249317, H5= 0249339.

Médias seguidas por letras distintas na coluna diferem entre si pelo teste $\operatorname{SNK}(\mathrm{P}<0,05)$.

Coeficiente de variação $=6,36 \%$

Os teores de $\mathrm{PB}$ do material original e das silagens dos cinco genótipos estão na Tab. 2. Não foi observada interação entre as diferentes épocas de abertura para os diferentes híbridos. O teor de PB do material original $(7,32 \%)$ foi maior que os das silagens $(6,44 \%)$ no $56^{\circ}$ dia $(\mathrm{P}<0,05)$.
Nos dias 1, 3, 5, 7, 14 e 28, esses teores variaram entre 6,66 e $6,93 \%$ e foram semelhantes aos dias 0 e $56(\mathrm{P}>0,05)$. H3 apresentou o maior teor médio de $\mathrm{PB}(\mathrm{P}<0,05)$, seguido por $\mathrm{H} 1, \mathrm{H} 4$ e $\mathrm{H} 5$ que apresentaram médias maiores que $\mathrm{H} 2$ $(\mathrm{P}<0,05)$.

Tabela 2. Proteína bruta do material original (PO) e das silagens dos cinco genótipos de sorgo, expressos na porcentagem da matéria seca, de acordo com o tempo de ensilagem

\begin{tabular}{cccccccccc}
\hline & \multicolumn{1}{c}{ Dia de abertura do silo } \\
Híbrido & P0 & 1 & 3 & 5 & 7 & 14 & 28 & 56 & Média \\
\hline H1 & 7,51 & 6,66 & 6,58 & 6,77 & 6,79 & 6,67 & 6,54 & 6,40 & $6,71 \mathrm{~b}$ \\
H2 & 6,38 & 6,09 & 5,88 & 5,86 & 6,27 & 6,47 & 5,89 & 5,73 & $6,07 \mathrm{c}$ \\
H3 & 8,33 & 7,07 & 7,53 & 8,21 & 6,85 & 7,15 & 8,05 & 6,53 & $7,46 \mathrm{a}$ \\
H4 & 7,08 & 6,77 & 7,27 & 6,95 & 7,04 & 6,83 & 6,93 & 6,54 & $6,92 \mathrm{~b}$ \\
H5 & 7,32 & 6,76 & 6,59 & 6,84 & 7,68 & 6,48 & 6,93 & 7,03 & $6,95 \mathrm{~b}$ \\
Média & $7,32 \mathrm{~A}$ & $6,67 \mathrm{AB}$ & $6,76 \mathrm{AB}$ & $6,93 \mathrm{AB}$ & $6,94 \mathrm{AB}$ & $6,66 \mathrm{AB}$ & $6,87 \mathrm{AB}$ & $6,44 \mathrm{~B}$ & 6,82 \\
\hline
\end{tabular}

$\mathrm{H} 1=\mathrm{BR} 700, \mathrm{H} 2=$ Volumax, $\mathrm{H} 3=0249341, \mathrm{H} 4=0249317, \mathrm{H} 5=0249339$.

Médias seguidas por letras distintas, maiúsculas na linha e minúsculas na coluna, diferem entre si pelo teste SNK $(\mathrm{P}<0,05)$.

Coeficiente de variação $=9,48 \%$

Os valores de PB obtidos neste trabalho assemelham-se aos valores, no material original $(6,07 \%)$ e na silagem $(8,43 \%)$, observados por Araújo (2002). Rocha Júnior et al. (2000b), ao trabalharem com sete genótipos de sorgo, com diferentes suculências de colmo, encontraram variações de 4,9 a 10,3\% para os teores de PB nas silagens. Silva (1996), ao utilizar sorgo de porte alto, obteve silagem com $6,49 \%$ de PB. Ferreira (2005), em silagens de sorgo de porte alto, também observou médias de PB menores que as observadas no presente estudo, porém com comportamento semelhante nos diferentes tempos de abertura.
De acordo com Van Soest (1994), o teor de PB não varia com o processo de ensilagem, apesar da possibilidade de as diferentes frações nitrogenadas serem alteradas. Observações semelhantes foram feitas por Borges (1995). Neste estudo a PB durante a ensilagem se manteve estável do primeiro ao $56^{\circ}$ dia $(\mathrm{P}>0,05)$, houve diferença apenas, quando se compararam os teores de $\mathrm{PB}$ do material original aos da silagem no $56^{\circ}$ dia $(\mathrm{P}<0,05)$. Possivelmente, essa diferença ocorreu por erro de amostragem ou volatilização de amônia na etapa de determinação da MS. 
Diferentes valores de PB no sorgo podem ser explicados pelas variações dos teores nas partes da planta. Bruno et al. (1992) mostraram que as partes com teor mais elevado de $\mathrm{PB}$, em vários cultivares de sorgo, foram as folhas seguidas pela panícula e pelos colmos.

Church (1988) cita teores mínimos de 7\% de proteína bruta para manutenção de adequado padrão de fermentação ruminal. No presente trabalho, apenas o híbrido $\mathrm{H} 2$ apresentou valores de PB bem abaixo do requisito descrito por este autor.
$\mathrm{Na}$ Tab. 3 podem ser visualizados os teores de $\mathrm{N}$ $\mathrm{NH}_{3} / \mathrm{NT}$ das silagens. Não foi observada interação entre épocas de abertura e híbridos. H2 apresentou teor $(2,75 \%)$ de $\mathrm{N}-\mathrm{NH}_{3} / \mathrm{NT}$ maior que os dos $\mathrm{H} 1, \mathrm{H} 2$ e $\mathrm{H} 5(\mathrm{P}<0,05)$. $\mathrm{H} 4$, com teor intermediário de $\mathrm{N}-\mathrm{NH}_{3} / \mathrm{NT}$, foi semelhante aos demais híbridos $(\mathrm{P}>0,05)$. No dia 56 , o teor de $\mathrm{N}-\mathrm{NH}_{3} / \mathrm{NT}$ foi maior que nos dias $1,3,5$ e 7 $(\mathrm{P}<0,05)$. Nos dias 14 e 28, esses valores foram intermediários e semelhantes a todos os períodos de abertura $(\mathrm{P}>0,05)$. $\mathrm{O}$ teor $\mathrm{N}-\mathrm{NH}_{3} / \mathrm{NT}$ apresentou correlação negativa $r=-0,2330$ com o conteúdo de matéria seca das silagens $(\mathrm{P}>0,05)$.

Tabela 3. Teores de nitrogênio amoniacal em relação ao nitrogênio total das silagens dos cinco genótipos de sorgo, de acordo com o tempo de ensilagem

\begin{tabular}{ccccccccc}
\hline & \multicolumn{8}{c}{ Dia de abertura do silo } \\
Híbrido & 1 & 3 & 5 & 7 & 14 & 28 & 56 & Média \\
\hline H1 & 1,09 & 1,35 & 1,33 & 1,51 & 1,62 & 1,74 & 2,01 & $1,52 \mathrm{~b}$ \\
H2 & 2,17 & 2,23 & 2,57 & 2,86 & 2,99 & 2,91 & 3,29 & $2,75 \mathrm{a}$ \\
H3 & 1,04 & 1,25 & 1,33 & 1,57 & 1,86 & 1,980 & 2,79 & $1,69 \mathrm{~b}$ \\
H4 & 2,28 & 1,37 & 1,44 & 1,63 & 1,84 & 1,840 & 3,66 & $2,01 \mathrm{ab}$ \\
H5 & 1,20 & 1,38 & 1,41 & 1,51 & 1,88 & 1,780 & 2,58 & $1,68 \mathrm{~b}$ \\
Média & $1,55 \mathrm{~B}$ & $1,51 \mathrm{~B}$ & $1,61 \mathrm{~B}$ & $1,82 \mathrm{~B}$ & $2,04 \mathrm{AB}$ & $2,05 \mathrm{AB}$ & $2,87 \mathrm{~A}$ & 1,92 \\
\hline
\end{tabular}

$\mathrm{H} 1=\mathrm{BR} 700, \mathrm{H} 2=$ Volumax, $\mathrm{H} 3=0249341, \mathrm{H} 4=0249317, \mathrm{H} 5=0249339$.

Médias seguidas por letras distintas, maiúsculas na linha e minúsculas na coluna, diferem entre si pelo teste SNK $(\mathrm{P}<0,05)$.

Coeficiente de variação $=57,4 \%$

Os teores de $\mathrm{N}-\mathrm{NH}_{3} / \mathrm{NT}$, observados neste experimento, foram menores que os relatados por Rocha Júnior et. al., 2000a; Silva, 1996 e Araújo et al., 2007.

De acordo com Oshima e McDonald (1978); AFRC (1987) e Henderson (1993), para a silagem ser considerada de boa qualidade, os teores de $\mathrm{N}-\mathrm{NH}_{3} / \mathrm{NT}$ devem atingir no máximo de 8 a $11 \%$. Baseando-se nessa informação, as silagens avaliadas podem ser consideradas como de bom padrão fermentativo, ou seja, com baixo índice proteolítico.

$\mathrm{Na}$ Tab. 4 são apresentados os valores de $\mathrm{pH}$ obtidos no suco das silagens. Não houve interação entre híbridos e épocas de abertura. H3 e $\mathrm{H} 5$ apresentaram médias de $\mathrm{pH} 4,2$, maiores que as observadas em $\mathrm{H} 2$ e $\mathrm{H} 4(\mathrm{P}<0,05)$. $\mathrm{H} 1$ com $\mathrm{pH}$ intermediário $(4,02)$, foi semelhante aos demais $(\mathrm{P}>0,05)$. $\mathrm{O}$ valor médio do $\mathrm{pH}$ diminuiu entre os dias 1 e $3(\mathrm{P}<0,05)$ e manteve-se estável nos demais períodos de abertura $(\mathrm{P}>0,05)$. Valores menores de $\mathrm{pH}$ foram descritos por Borges (1995) que observou variações entre 3,63 e 3,67 no $56^{\circ}$ dia de ensilagem. Silva (1996), também relatou menores valores de $\mathrm{pH}$. Araújo et al. (2007), ao trabalharem com silagem de sorgo obtida no estádio de grãos farináceos, relatou valores de $\mathrm{pH}$ entre 3,89 e 4,07. Ferreira (2005), ao utilizar seis genótipos de sorgo de porte alto, obteve média de 3.92 .

Segundo McDonald et al. (1991), quando há altos teores de açúcares e baixos de proteína, a estabilização da fermentação ocorre antes de 10 dias de ensilagem. Muck (1988) cita que a diminuição normal do $\mathrm{pH}$ ocorre nos primeiros cinco dias de ensilagem. A rápida queda do $\mathrm{pH}$ é fator desejável para que haja a interrupção das fermentações indesejáveis e conseqüente preservação da silagem. Neste experimento a estabilização ocorreu entre o terceiro e o sétimo dia. 
Padrão de fermentação da silagem...

Tabela 4. Valores de pH das silagens dos cinco genótipos de sorgo, de acordo com o tempo de ensilagem

\begin{tabular}{ccccccccc}
\hline & \multicolumn{7}{c}{ Dia de abertura do silo } \\
Híbrido & 1 & 3 & 5 & 7 & 14 & 28 & 56 & Média \\
\hline H1 & 4,58 & 4,08 & 3,75 & 3,93 & 4,02 & 3,93 & 3,89 & $4,02 \mathrm{ab}$ \\
H2 & 4,28 & 3,92 & 3,79 & 3,71 & 3,80 & 3,79 & 3,69 & $3,85 \mathrm{~b}$ \\
H3 & 4,42 & 4,05 & 4,00 & 3,94 & 4,24 & 4,41 & 4,34 & $4,20 \mathrm{a}$ \\
H4 & 4,19 & 3,79 & 3,73 & 3,71 & 3,86 & 3,82 & 3,83 & $3,84 \mathrm{~b}$ \\
H5 & 4,40 & 4,06 & 4,03 & 3,99 & 4,26 & 4,17 & 4,52 & $4,20 \mathrm{a}$ \\
Média & $4,37 \mathrm{~A}$ & $3,98 \mathrm{~B}$ & $3,86 \mathrm{~B}$ & $3,85 \mathrm{~B}$ & $4,03 \mathrm{~B}$ & $4,02 \mathrm{~B}$ & $4,05 \mathrm{~B}$ & 4,02 \\
\hline
\end{tabular}

H1= BR700, H2= Volumax, H3= 0249341, H4= 0249317, H5= 0249339.

Médias seguidas por letras distintas, maiúsculas na linha e minúsculas, na coluna diferem entre si pelo teste SNK $(\mathrm{P}>0,05)$.

Coeficiente de variação $=6,86 \%$

$\mathrm{Na}$ Tab. 5 podem ser observados os valores de CHOs obtidos do material original e das silagens dos cinco genótipos de sorgo. Houve interação entre os híbridos e épocas de abertura. Os maiores teores de $\mathrm{CHOs}$ foram observados no $\mathrm{H} 2$, no material original e em todos os períodos de abertura dos silos $(\mathrm{P}<0,05)$.

Tabela 5 - Valores de carboidratos solúveis do material original (PO) e das silagens dos cinco genótipos de sorgo, expressos na porcentagem da matéria seca, de acordo com o tempo de ensilagem

\begin{tabular}{cccccccccc}
\hline \multicolumn{7}{c}{ Dia de abertura do silo } \\
Híbrido & $\mathrm{P} 0$ & 1 & 3 & 5 & 7 & 14 & 28 & 56 & Média \\
\hline $\mathrm{H} 1$ & $2,75 \mathrm{Ab}$ & $1,99 \mathrm{ABb}$ & $0,81 \mathrm{BCb}$ & $1,02 \mathrm{BCb}$ & $0,03 \mathrm{Cc}$ & $0,02 \mathrm{Cc}$ & $0,15 \mathrm{Cc}$ & $0,08 \mathrm{Cc}$ & $0,85 \mathrm{~b}$ \\
$\mathrm{H} 2$ & $8,32 \mathrm{Aa}$ & $7,76 \mathrm{Aa}$ & $3,51 \mathrm{Ba}$ & $3,92 \mathrm{Ba}$ & $3,05 \mathrm{Ba}$ & $2,80 \mathrm{Ba}$ & $2,22 \mathrm{BCa}$ & $1,43 \mathrm{Ca}$ & $4,12 \mathrm{a}$ \\
$\mathrm{H} 3$ & $2,57 \mathrm{Ab}$ & $0,98 \mathrm{Bb}$ & $0,66 \mathrm{Bb}$ & $1,54 \mathrm{ABb}$ & $0,26 \mathrm{Bb}$ & $0,12 \mathrm{Bb}$ & $0,08 \mathrm{Bb}$ & $0,05 \mathrm{Bb}$ & $0,78 \mathrm{~b}$ \\
$\mathrm{H} 4$ & $2,05 \mathrm{ABb}$ & $2,55 \mathrm{Ab}$ & $0,76 \mathrm{BCb}$ & $1,24 \mathrm{ABCb}$ & $0,15 \mathrm{Cb}$ & $0,22 \mathrm{Cb}$ & $0,20 \mathrm{Cb}$ & $0,10 \mathrm{Cb}$ & $0,91 \mathrm{~b}$ \\
$\mathrm{H} 5$ & $1,51 \mathrm{Ab}$ & $1,11 \mathrm{Ab}$ & $0,66 \mathrm{Ab}$ & $1,07 \mathrm{Ab}$ & $0,20 \mathrm{Ab}$ & $0,15 \mathrm{Ab}$ & $0,09 \mathrm{Ab}$ & $0,24 \mathrm{Ab}$ & $0,62 \mathrm{~b}$ \\
Média & $3,44 \mathrm{~A}$ & $2,87 \mathrm{~B}$ & $1,28 \mathrm{CD}$ & $1,75 \mathrm{C}$ & $0,73 \mathrm{DE}$ & $0,66 \mathrm{DE}$ & $0,54 \mathrm{E}$ & $0,37 \mathrm{E}$ & 1,46 \\
\hline
\end{tabular}

$\mathrm{H} 1=\mathrm{BR} 700, \mathrm{H} 2=$ Volumax, $\mathrm{H} 3=0249341, \mathrm{H} 4=0249317, \mathrm{H} 5=0249339$.

Médias seguidas por letras distintas, maiúsculas na linha e minúsculas na coluna, diferem entre si pelo teste SNK $(\mathrm{P}>0,05)$

Coeficiente de variação $=40,43 \%$

Maiores teores de CHOs foram encontrados por Rodriguez et al. (1997), ao trabalharem com híbridos de duplo propósito, sendo que $9,45 \%$ foi o maior valor no material original e 1,23\% o menor valor observado no $14^{\circ}$ dia após a ensilagem. A estabilização da queda dos teores de CHOs aconteceu a partir do sétimo dia, semelhante ao comportamento dos híbridos deste experimento. Meskee et al. (1993) verificaram, em sorgo de porte alto, queda acentuada dos CHOs até o quinto dia, seguida de redução mais branda até o $31^{\circ}$ dia.

Além das variações existentes entre espécies, os fatores que mais influenciam os teores de $\mathrm{CHOs}$ são os cultivares, o estádio de maturação, a luminosidade, a temperatura, a aplicação de fertilizantes e a precipitação pluviométrica (McDonald et al., 1991; Haigh, 1990). O grau de desaparecimento dos açúcares solúveis depende do tipo de microorganismo, da condição de anaerobiose, do tempo de ensilagem, do teor de matéria seca e da capacidade tamponante da planta.

De acordo com Gourley e Lusk (1977), são necessários 6 a $8 \%$ de CHOs para que ocorra rápida e desejada queda dos valores de $\mathrm{pH}$. Neste experimento, apenas o híbrido $\mathrm{H} 2$ apresentou os valores desejáveis. Isto significa que, 
provavelmente o abaixamento do $\mathrm{pH}$ das silagens deveu-se também à fermentação de carboidratos adicionais, oriundos, principalmente, da hidrólise de hemiceluloses (McDonald et al., 1991).

\section{CONCLUSÕES}

Os híbridos avaliados têm potencial para produção de silagem em função dos teores de matéria seca, proteína bruta, nitrogênio amoniacal em relação ao nitrogênio total, $\mathrm{pH}$ e carboidratos solúveis que são satisfatórios para o padrão de fermentação.

\section{REFERÊNCIAS BIBLIOGRÁFICAS}

AFRC. Technical committee on responses to nutrients. Report 2. Characterization of feedstuffs. Nutr. Abstr. Rev., Series B., v.57, p.713-736, 1987.

ARAÚJO, V.L. Momento de colheita de três genótipos de sorgo para produção de silagem. 2002. 47f. Dissertação (Mestrado) - Escola de Veterinária, Universidade Federal de Minas Gerais, Belo Horizonte.

ARAÚJO, V.L.; RODRIGUEZ, N.M.; GONÇALVES, L.C. et al. Qualidade das silagens de três híbridos de sorgo ensilados em cinco diferentes estádios de maturação. Arq. Bras. Med. Vet. Zootec., v.59, p. 168-174, 2007

BAILEY, R.W. Quantitative studies of ruminant digestion. II. Loss of ingested plant carbohydrate from the reticule rumen. N. Z. J. Agric. Res., v.10, p.15-32, 1967.

BORGES, A.L.C.C. Qualidade de silagem de híbridos de sorgo de porte alto, com diferentes teores de tanino e de umidade no colmo, e seus padrões de fermentação. 1995. 104f. Dissertação (Mestrado) - Escola de Veterinária da Universidade Federal de Minas Gerais, Belo Horizonte.

BRUNO, O.A.; ROMERO, L.A.; GAGGIOTI, M.C. et. al. Cultivares de sorgo forrajeros para silaje. I - rendimento de materia seca y valor nutritivo de la planta. Rev. Argent. Prod. Anim., v.12, p.157-162, 1992.

CARVALHO, D.D.; ANDRADE, J.B.; BIONDI, P. et. al.. Estádio de maturação na produção e qualidade da silagem de sorgo. I - Produção de matéria seca e proteína bruta. Bol. Ind. Anim., v.49, p.91-99, 1992.

CHURCH, D.C. (Ed). The ruminant animal digestive physiology and nutrition. New Jersey: Prentice Hall, 1988. $564 \mathrm{p}$.

FERREIRA, J.J.C. Avaliação da qualidade e do perfil de fermentação das silagens de seis cultivares de sorgo. 2005. 57f. Dissertação (Mestrado) - Escola de Veterinária da Universidade Federal de Minas Gerais, Belo Horizonte.

GOURLEY, L.M., LUSK, J.W. Sorghum silage quality as affected by soluble carboydrate, tannins, and other factors. In: ANNUAL CORN AND SORGHUM RESEARCH CONFERENCE, 32., Mississipi Proceedings..., Mississipi: State University, 1977. p.157-170.
HAIGH, P.M. Effect of herbage water-soluble carbohydrate content and weather coonditions at ensilage on the fermentation of grass silages made on commercial farms. Grass Forage Sci., v.45, p.263-271, 1990.

HENDERSON, N. Silage Aditives. Anim. Feed Sci. Technol. v.68, n. 1 , p. $35-56,1993$.

McDONALD, P.; HENDERSON, A.R.; HERON, S.J.E. (Eds). The Biochemistry of silage. Marlow: Chalcombe Publications, 1991. 340p.

McKERSIE, B.D. Effect of $\mathrm{pH}$ on proteolysis in ensiled legume forage. Agron. J., v.77, p.81-86, 1985.

MEESKE, R., ASHBELL, G., WEINBERG, Z.G., et al. Ensiling forage sorghum at two stages of maturity with the addition of lactic acid bacterial inoculants. Anim. Feed Sci. Technol., v.43, p.165-175, 1993.

MUCK, R.E. Factors influencing silage quality and their implications for management. J. Dairy Sci. v.71, p.2992$3002,1988$.

OFFICIAL methods of analysis. 13.ed. Washington: AOAC, 1980. 1015 p.

OSHIMA, M.; McDONALD, P. A review of the changes in nitrogenous compounds of herbage during ensilage. J.Sci. Food Agric., v.29, p.497-508, 1978.

PAIVA, J.A.J. Qualidade do sorgo da região metalúrgica de Minas Gerais. 1976. 83f. Dissertação (Mestrado) - Escola de Veterinária da Universidade Federal de Minas Gerais, Belo Horizonte.

PIZARRO, E. A. Alguns fatores que afetam o valor nutritivo da silagem de sorgo. Inf. Agropecu. v.47, p.12-19, 1978.

PETTERSON, K. L.; LINDGREN, S. The influence of the carbohydrate fraction and additives on silage quality. Grass Forage Sci., v.45, p.223-233, 1989.

ROCHA JUNIOR, V.R.; GONÇALVES, L. C.; RODRIGUES, J.A.S. et al. Avaliação de sete genótipos de sorgo (Sorghum bicolor (L.) Moench) para produção d silagem II. Padrão de fermentação. Arq. Bras. Med. Vet. Zootec., v.52, p.512-520, 2000a.

ROCHA JUNIOR, V.R.; GONÇALVES, L.C.; RODRIGUES, J.A.S. et al. Avaliação de sete genótipos de sorgo (Sorghum bicolor (L.) Moench) para produção d silagem III. Valor nutricional. Arq. Bras. Med. Vet. Zootec., v.52, p. 627-633, 2000 b.

RODRIGUEZ, N.M.; BERNARDINO, M.L.A.; GONÇALVES, L.C. et. al. Silagem de sorgo de porte médio com diferentes teores de tanino e suculência no colmo. II. Curva de fermentação de carboidratos e lignina. Arq. Bras. Med. Vet. Zootec., v.49, p.317-329, 1997.

SILVA, A.V. Qualidade das silagens de treze genótipos de sorgo [Sorghum bicolor (L.) Moench]. 1996. 98f. Dissertação (Mestrado) - Escola de Veterinária da Universidade Federal de Minas Gerais, Belo Horizonte.

SISTEMA de análises estatísticas e genéticas - SAEG. Versão 8.0. Viçosa: UFV, 1998.

VAN SOEST, P.J. Nutrition and ecology of the ruminant. 2.ed., Ithaca: Cornell University, 1994. 476p. 